(2) Open Access Full Text Article

REVIEW

\title{
Immunoglobulin G2 Antibody as a Potential Target for COVID-19 Vaccine
}

This article was published in the following Dove Press journal:

ImmunoTargets and Therapy

\author{
Henok Andualem (D) \\ Mulugeta Kiros $\mathbb{D}^{2}$ \\ Sisay Getu ${ }^{3}$ \\ Wasihun Hailemichael (D) \\ 'Immunology and Molecular Biology, \\ Department of Medical Laboratory \\ Science, College of Health Science, \\ Debre Tabor University, Debre Tabor, \\ Ethiopia; ${ }^{2}$ Medical Microbiology, \\ Department of Medical Laboratory \\ Science, College of Health Science, \\ Debre Tabor University, Debre Tabor, \\ Ethiopia; ${ }^{3}$ Clinical Hematology and \\ Immunohematology, Department of \\ Medical Laboratory Science, College of \\ Health Science, Debre Tabor University, \\ Debre Tabor, Ethiopia
}

\begin{abstract}
The global threat of COVID-19 is continued with no commercially available vaccine or drug yet. While the application of convalescent therapy is usually beneficial, for critically ill patients, the detrimental effect associated with some antibodies is also reported. The immunoglobulin $\mathrm{G}$ ( $\mathrm{IgG})$ antibody in response to severe acute respiratory syndrome coronavirus-2 (SARS-CoV-2) infection is described, albeit the lack of defining whether the difference in subclasses has a beneficial or detrimental role. IgG2 has limited ability to activate innate immune cells and complement-mediated inflammation, which have been inversely described in SARS-CoV-2 pathogenesis. The expansion of IgG2 is promoted by interferon $\gamma$ (IFN- $\gamma$ ); however, there is a low level of IFN- $\gamma$ in COVID-19 patients. Therefore, this review describes the importance of targeting IgG2, with IFN- $\gamma$ in minimizing the SARS-CoV-2 associated inflammation, and may provide insight into the design of vaccine or antibody-based therapies to COVID-19 disease.
\end{abstract}

Keywords: IgG2, IFN- $\gamma$, antibody therapy, COVID-19 vaccine

\section{Introduction}

From the mid-1890s passive immunization has been used for the treatment of various bacterial and viral infections, when there were no anti-microbial treatments available. ${ }^{1}$ In particular, the use of convalescent sera (CS) collected from recovered individuals was recommended by world health organization (WHO) as an empirical treatment for Ebola virus by $2014 .^{2}$ This approach has also been applied and was effective for other viral infections, such as influenza A H1N1, avian influenza H5N1, and SARS-CoV. ${ }^{3-5}$ Given the clinical and viral sequence homologue between SARS-CoV, MERS-CoV, and SARS-CoV-2, it has recently been used for the treatment of severely infected patients with SARS-CoV-2, the etiologic agent of COVID-19 disease. ${ }^{6}$ The transfusion of CS is associated with diminished viral load, serum cytokine response, length of hospital stays, and death. ${ }^{7}$ One of the presumable explanations for this success is the presence of neutralizing antibodies $(\mathrm{Nab})$ because an increment of virus-specific Nab titer and vanishing of viremia was observed. $^{6}$

Besides, the antibody response to some viruses, including SARS-CoV-2 has a detrimental role, the state of antibody-dependent enhancement (ADE). It is not only been the most frequently mentioned challenge during infections but also in the area of antibody therapy or antibody-based vaccines. ${ }^{8}$ Among antibody types, the presence of $\mathrm{IgG}$ antibodies to $\mathrm{S}$ and $\mathrm{N}$ protein is being used as a diagnostic and indicative of long-term SARS-CoV-2 infection. ${ }^{9}$ Moreover, the high level of this
Correspondence: Henok Andualem Immunology and Molecular Biology, Department of Medical Laboratory Science, College of Health Science, Debre Tabor University, Debre Tabor, Ethiopia Tel +25192325I524

Email henokyaa@yahoo.com
ImmunoTargets and Therapy 2020:9 |43-149 
antibody is correlated with worsen clinical outcome. ${ }^{10}$ In contrast, the majority of patients who recovered from mild SARS-CoV-2 infection exhibited a high level of neutralizing antibodies. ${ }^{11}$ However, it is not clearly described whether high- level $\mathrm{IgG}$ is correlated with protection from SARS-CoV-2 infection or not. ${ }^{12}$ As reported from a clinical trial, there are antibodies with or without ADE effect, although the classes or subclasses are not characterized. ${ }^{13}$ Remarkably, the IgG response that comprises IgG2 mostly appeared lower activation of innate immune cells, such as neutrophil, and complement pathway. ${ }^{14}$ However, the activation of these cells, and the corresponding hyper-production of cytokines, including tumor necrosis factor $\alpha$ (TNF- $\alpha$ ) and interleukin 6 (IL-6), was correlated to acute respiratory distress syndrome (ARD) and death in SARS-CoV-2 infection. ${ }^{15}$ This indicates the induction of IgG2 may reduce the ADE.

Furthermore, the class-switching of $\operatorname{IgG} 2$ is enhanced by IFN- $\gamma$. The spike glycoprotein (S) of SARS-CoV-2 is the frequent target for COVID-19 vaccines under different lines of clinical trials. ${ }^{16}$ Therefore, $\mathrm{S}$ based vaccines with the IFN- $\gamma$ encoding gene, along with ensuring the high level of IgG2 antibodies could have paramount importance for immune-related disease, including COVID-19. However, there is a lack of data on defining the role of IgG2 in SARS-CoV-2 infection or vaccination. In this review, we aimed to discuss the role of $\mathrm{IgG} 2$ in reducing the effect of $\mathrm{ADE}$ and its function towards modulating immune-pathologies associated with COVID-19 disease.

\section{Antibodies-Based Pathogenesis}

Antibodies are serum proteins, capable of a bind and neutralize heterogeneous strains of a given pathogen with highly unstable immunogenicity. ${ }^{17}$ In addition to the clearance of free virus and block new infection, they are also involved in the expedite of infected cell clearance, as observed in vivo trial for HIV infection. ${ }^{18}$ This is also demonstrated in mouse model SARS-CoV, where antibody induces antibody-dependent cytotoxicity (ADCC) mediated lysis of infected cells mediated via interaction with phagocytes, such as macrophages. ${ }^{19}$ Beyond this, antibodies are introduced in therapeutic era and effective for treatment of many infectious and non-infectious diseases ${ }^{20}$ discussed later in this review.

The antibody therapies, including convalescent sera and immunoglobulin therapy, are not without drawbacks, and the most frequent scenario is an antibody-dependent enhancement (ADE). Antibodies are supposed to control the spread and prevention of infection. Instead, preexisting antibodies augment the internalization of the virus into the host cells, which is an alternative way of immune-mediated viral infection, called ADE. Many viruses, including dengue, HIV, Ebola, and influenza A take advantage of ADE as a means of infecting host cells. The precise mechanism of ADE is yet undefined. The most frequently mentioned mechanism is linked to the binding of virus bound antibody to Fc receptors on the surface of immune cells, activates them, and also complement pathway. ${ }^{21}$

ADE has also been observed in SARS-CoV infection particularly by antibodies against $\mathrm{S}$ protein. The $\mathrm{Fc}$ portion of anti- $\mathrm{S}$ antibodies have been shown to activate and infect immune cells, including monocytes, macrophage, and $\mathrm{B}$ cells via FcRs, which promote inflammation and tissue injury. ${ }^{22}$ This mechanism of infection was independent of utilizing the angiotensin I converting enzyme 2 (ACE2), known receptor for SARS-CoV and SARS-CoV $-2 .^{23}$ These evidences indicate several factors would come into consideration to wipe out the effect of ADE while keeping antibodies ability to neutralize the virus and protects the host. These may include the concentration, avidity, affinity, and isotypes of the antibodies.

\section{Roles of IgG2 in Infectious Diseases}

It is well known that each isotype of antibodies has distinct effector functions. Generally, the $\operatorname{IgG}$ response that involves the $\operatorname{IgG} 2$ subclass is associated with a noninflammatory response. ${ }^{14}$ Despite that IgG2 usually participates in protection against carbohydrate antigens like bacterial capsular polysaccharide, it is also involved in response to protein antigens. ${ }^{24}$ Its effector function is largely mediated by activating the Fc $\gamma$ RIIa (CD32) receptor, and the IgG deficiency has been linked to the susceptibility of some diseases, such as Haemophilus influenzae type $b$ (Hib) infections, ${ }^{25}$ and the failure to develop immunity when vaccination for Hib. ${ }^{26}$ Apart from the effect of antibody isotypes, genetic variation in FcRs can also affect the interaction of FcRs with IgG subclasses, and thereby alter the effector function to whether pathologic or immune protection. For instance, allelic polymorphisms in the FcyRIIa are associated with the sever course of SARS-CoV. ${ }^{27}$

In addition to bacterial infections, the role of $\operatorname{IgG} 2$ has been also described in viral infections, such as HIV, where HIV infected children displayed selective deficiency of IgG2 with a normal level of total IgG. $^{28}$ The high level 
of IgG2 is very uncommon in $\mathrm{HIV}$, as the class-switching is highly inhibited by the virus. ${ }^{29}$ However, the high level of IgG2 antibodies to Gp41 was inversely correlated with HIV disease progression. ${ }^{30}$ In SARS-CoV infection, a study showed that individuals with FcrRIIa that can bind only IgG2 have shown less severe as compared to individuals with FcyRIIa that bind to both IgG1 and IgG2. ${ }^{27}$ Furthermore, although the antibodies' response to SARS-CoV-2 infection is not fully elucidated, various studies reported the seroconversion of $\operatorname{IgM}$ and $\operatorname{IgG}$, which reaches the peak level within 14 days of infection. ${ }^{31}$ It remains to be determined that the presence of these antibodies have a protective role or not.

\section{IgG2 and IFN- $\gamma$ in SARS-CoV-2 Infection}

The infection with SARS-CoV-2 is characterized by hyper-expression of cytokines, such as IL-6, TNF- $\alpha$, IL$1 \beta$, and IP-10, along with chemokines, such as IP-10, with a higher level in those who are severely ill. ${ }^{32-34}$ Viral infections are usually mediated by Th1 response; however elevated Th2 cytokines, including IL-4 and IL-10, are also reported in COVID-19 patients. ${ }^{35}$ Consequently, the appearance of "cytokine storm", this is where cytokines are produced in higher amounts. The cytokine storm is linked to heightened inflammatory responses, acute respiratory distress syndrome (ARD), and even death. ${ }^{15}$

Similar to SARS-CoV and MERS-CoV, SARS-CoV-2 provokes the seroconversion for $\mathrm{IgG}$ and $\mathrm{IgM}$ in the majority of infected patients after 2 weeks of symptoms onset. $^{31}$ The antibodies are produced against the spike (S) followed by nucleocapsid (N) proteins. The high level of anti-N IgG is found from non-intensive care unit (ICU) patients, while the anti-S IgG in patients who require ICU. ${ }^{36}$ Also, the appearance of $\operatorname{IgG}$ on day 7 and stronger titer is correlated with delayed viral clearance and COVID-19 disease severity. ${ }^{37,38}$ This indicates there is a likelihood of ADE involvement in SARS-CoV-2 infection. ${ }^{39}$ In both SARS and MERS, pre-existing anti-S IgG antibodies, particularly IgG1 and IgG3 subclasses shown to facilitate uptake of the virus, and infection of macrophages, monocytes, and B cells. These antibodies also activate complement via complement receptor and cause ADE, which was linked to the occurrence of cytokine storm. ${ }^{40}$ It needs to be determined whether IgG subclasses have a determinantal or beneficial effect for SARSCoV-2 infection.
Furthermore, the sequencing of SARS-CoV S glycoprotein, followed by vaccination with immunodominant peptides has induced a combination of IgG antibodies with neutralization and ADE effects. Notably, from these antibodies, IgG2 exclusively belongs to only neutralization, whereas $\operatorname{IgG1}$ and other subclasses were with both neutralization and ADE effects. ${ }^{13}$ This indicates, unlike $\operatorname{IgG} 1, \operatorname{IgG} 4$, and $\operatorname{IgG} 3, \operatorname{IgG} 2$ response is related to the minimal effect of ADE.

The production of IgG2 is enhanced by interferon- $\gamma$ $($ IFN- $\gamma)$. IFNs are the crucial innate immune defense against viral infections, particularly in the early stages. ${ }^{41}$ However, in cases of SARS and MERS, studies have demonstrated delayed expression and production of type I IFN, and thereby delay the overall host antiviral response. $^{42}$ In SARS-CoV-2, contradictory results are reported. The earlier study showed the low level of innate anti-viral defense, including the level of type I IFN, ${ }^{43}$ while a recent study reported the hyperexpression of interferon stimulating genes (ISGs). ${ }^{32}$ Further, a very low level of IFN-I is found in critically ill patients, ${ }^{44}$ with a high viral load. More specifically, the variable pattern of IFN $-\alpha$, low level of IFN- $\gamma$, and undetectable IFN- $\beta$ and $\lambda$ were observed in SARS-CoV-2 infected patients. ${ }^{34}$ Besides, early administration of IFN-I prevented lung inflammation in a murine model of SARS-CoV infection. ${ }^{45}$ In vitro, the greater sensitivity of SARS-CoV-2 to type I IFN was recorded, as compared to SARS-CoV ${ }^{46}$ At the cellular level, diminished frequency of IFN- $\gamma^{+}$natural killer and CD8 T-cells is reported. ${ }^{33}$ Despite the controversy, it seems clear that the lack of IFN-I has a great impact on SARS-CoV-2 infection, raising the possibility that the early administration of IFN-I is valuable for infected patients.

\section{Antibody-Based Therapies}

Due mainly to the high avidity and specificity, monoclonal antibodies (mAbs) have been selected as an alternative therapeutic option, to CS therapy. Several mAbs are commercially available for the treatment of various diseases, including cancer, autoimmune, and infectious disease. The majority of these Abs are human IgG1 subclass. ${ }^{20}$ In improving the safety, several efforts have been made to tailor the properties of mAbs, including modification or removal of $\mathrm{Fc}$ induced effectors, with an affinity similar to the whole $\mathrm{mAb} \cdot{ }^{47}$ These efforts include the preparation of single-chain variable fragments (scFvs) and the Fc engineered antibodies. scFvs are small-sized and lack the Fc region, enabling in 
tissue penetration and rapid clearance from circulation, since the interaction with $\mathrm{Fc}$ receptors (like neonatal FcR) affects the half-life. Therefore, these fragments are not only targets but also fused to many molecules, such as drugs, radionuclides for cancer treatment, enzymes for improved drug delivery, and also viruses for gene therapy. ${ }^{48}$ Currently, the use of a single or combination of mAb for COVID-19 is under the first phase of human trials. ${ }^{49}$

Despite scFvs are less costly and flexible in use, the halflife is relatively fewer than Fc engineered mAbs. The Fc is engineered, in some time to enhance effector functions and increase the half-life. Another time, the reduction of functions, such as ADCC is required, along with half-life. ${ }^{47}$ Among the $\mathrm{Fc}$ engineering to reduce effector functions, a cross-subclass approach that involves IgG2 to $\mathrm{IgG} 4$ resulted in undetectable complement-dependent cellmediated cytotoxicity (CDC), antibody-dependent cellmediated cytotoxicity (ADCC), and antibody-dependent cellular phagocytosis (ADCP) in experimental models. ${ }^{50,51}$ Therefore, an antibody therapy that contains mAb of which its $\mathrm{Fc}$ is modified to reduce the effector functions and increased half-life, adverse consequences of the therapy, such as ADE, could be declined. Moreover, although IgG2 based therapy has not been applied for coronaviruses, seems it shares these features without modification and might be a preferable target, as mentioned in Figure 1.

\section{Targeting IgG2: Implication for COVID-I 9 Vaccine/Immunotherapy}

Given the above shreds of evidence, one can assume that therapies targeted to IFN- $\gamma$ and IgG2 might help harness the aggressive inflammatory reactions, such as SARS-CoV -2 . Among the different approaches of vaccine designs, the subunit vaccine has a long history of success for viral infections, including the recombinant hepatitis B vaccine

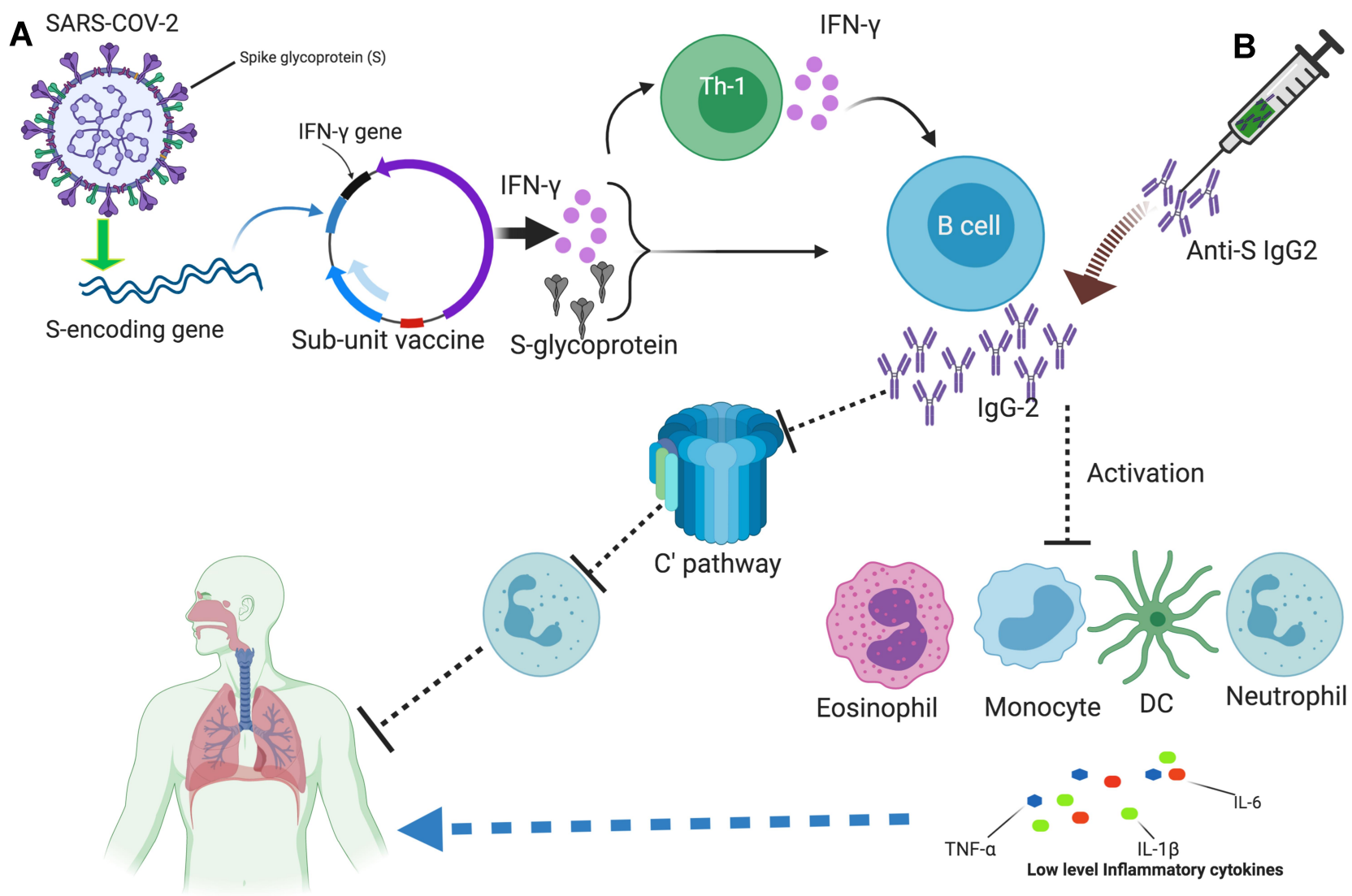

Diminished Lung inflammation

Figure I An overview of targeting IgG2 for COVID-19 vaccine: (A) The structure of SARS-CoV-2 with its proteins is shown on the upper left corner, As S-glycoprotein is a frequent target, the $\mathrm{S}$ encoding gene, and the IFN- $\gamma$ gene inserted in a plasmid, is depicted, as sub-unit vaccine. The expression of these genes leads to the activation of ThI and $B$ cells, thus $\lg G 2$. (B) The adoptive transfer of anti-S IgG2 is shown on the upper right corner, like a needle containing antibodies. The expansion of lgG2 reduces the activation of immune cells like monocytes, neutrophil, eosinophil, and DC, and their cytokine expression. IgG2 also blocks the activation of complement-mediated recruitment of the neutrophils into the lung. All these are attributable to low inflammatory responses and the protection of lung inflammation. The picture is created at https://biorender.com/. 
(rDNA) ${ }^{52}$ Usually, designing of vaccine or immunotherapy anticipated in targeting the surface molecules limits the anchoring of microbes into cellular receptors. ${ }^{53}$

Nowadays, vaccines for COVID-19 are under fast development, which is mainly based on the experiences of SARS and MERS vaccines. The majority of these targets S glycoprotein, and coffered better immunogenicity. ${ }^{16}$ These include vectored recombinant adenovirus type-5 (Ad5), virus-like nanoparticles, trimerized SARS-CoV-2 S-protein, and only the receptorbinding domain (RBD) portion of $\mathrm{S}$ based vaccine. ${ }^{53-55}$ The virus-like nanoparticle and $\mathrm{Ad} 5$ vaccines induced a high level of IgG antibodies after 35 and 28 days of vaccination, respectively. ${ }^{53}$ Despite the debate in the optimization of S-glycoprotein whether to use full length or RBD region, and the progress is still on Phase I clinical, considerable efficacy has been recorded, which is primarily mediated by antibodies.

The S glycoprotein, chemically composed of protein and carbohydrate, and B cells response to carbohydrate antigens usually render the class-switching of $\operatorname{IgG} 2{ }^{24}$ Compare to other subclasses, the IgG2 antibody has a lower affinity to Fc $\gamma$ RIIa, which is expressed by neutrophil, basophil, eosinophil, monocytes, and dendritic cells. ${ }^{56}$ Consequently, the low level of activation of these cells could be attributable to low inflammatory response than high activation. The high level of IgG2 antibodies produces low activation of the complement pathway, and inhibition of complement activation is correlated with the reduced pathogenesis of SARS-CoV, such as reduced viral load, neutrophilia in lungs, and reduced systemic inflammation. ${ }^{57}$ Furthermore, protection from a disease has also been recorded, where there is higher production of $\mathrm{IgG} 2$ against the glycoprotein of Maedi- visna virus in sheep. ${ }^{58}$ While, the immune complex of IgG4 that binds to Fc $\gamma$ RIIa has shown to cause cytokine storm, in anti-CD28 IgG4 therapy. ${ }^{59}$

In addition to focusing on the $\mathrm{S}$ region and targeting $\mathrm{IgG}$, incorporating molecules with immune-potentiation outcomes might add extra value for the success of COVID-19 vaccines. For instance, insertion of the IFN- $\gamma$ gene. It is well known that the class-switching of antibodies highly depends on the cytokine milieu. IFN- $\gamma$ induces the class-switching of $\operatorname{IgG} 2$, at the same level of inhibition of IL-4 induced production of IgG1 ${ }^{60}$ In a randomized clinical trial, the vaccination with rFPV that encoding HIV Gag-Pol and IFN- $\gamma$ results in the production of IgG2 antibodies to P24 antigen, and these antibodies exhibited control of HIV replication in HIV patients. ${ }^{61}$ Further, a in HIV clinical trial showed, the transfer of recombinant CD4-IgG2 antibody successfully reduced HIV viral load. ${ }^{62}$ Similarly, in pig and human model of inflammation, IgG1 therapy with a hybrid $\mathrm{Fc}$ portion, which consists of sequences from human IgG2 and IgG4 considerably reduced the inflammatory response. ${ }^{63}$ In a recent study, potent neutralizing antibodies are identified from SARS$\mathrm{CoV}-2$ recovered human donors, and the passive transfer establishes protection against disease in high-dose SARSCoV-2 challenge in Syrian hamsters. ${ }^{64}$ So, it may reasonable to consider $\operatorname{IgG} 2$ in designing not only antibody therapies but also vaccines for SARS-CoV-2.

\section{Concluding Marks}

Overall, the effectiveness of clinical trials with vaccine or immunotherapy for COVID-19 may be enhanced through incorporating genes encoding IFN- $\gamma$, while keeping the high level of IgG2 antibody. More specifically, the vaccine-induced IgG2 antibody needs to be assessed in the process of clinical trials for S glycoprotein-based SARS$\mathrm{CoV}-2$ vaccines. The limited effector functions of IgG2 could improve the safety of the vaccine, by reducing ADE. Moreover, the adoptive transfer of anti-S IgG2 may contribute to the prophylaxis and/or recovery of COVID-19 patients. Although targeting the S glycoprotein has already been established, an experimental study on the enrichment of IgG2 class-switching by IFN- $\gamma$ and/or other molecules is warranted when designing a vaccine for SARS-CoV-2.

\section{Abbreviations}

ADE, antibody-dependent enhancement; COVID-19, coronavirus disease 2019; Fc $\gamma$ R-IIa, Fc gamma receptor II A; HIV, human immunodeficiency virus; IFN- $\gamma$, interferongamma; IgG, immunoglobulin G; SARS-CoV-2, severe acute respiratory syndrome 2 .

\section{Author Contributions}

All authors made a significant contribution to the work reported, whether that is in the conception, study design, execution, acquisition of data, analysis and interpretation, or in all these areas; took part in drafting, revising orcritically reviewing the article; gave final approval of the version to be published; have agreed on the journal to which the article has been submitted; and agree to be accountable for all aspects of the work. 


\section{Funding}

The authors received no specific fund this work.

\section{Disclosure}

The authors report no potential conflicts of interest for this work.

\section{References}

1. Simon J. Emil Behring's medical culture: from disinfection to serotherapy. Med Hist. 2007;51(2):201-218. doi:10.1017/S0025727300001198

2. WHO. Use of convalescent whole blood or plasma collected from patients recovered from Ebola virus disease for transfusion, as an empirical treatment during outbreaks; 2014. Available from: https:// www.who.int/csr/resources/publications/ebola/convalescenttreatment/en/. Accessed September 5, 2020.

3. Hung IF, To KK, Lee C-K, et al. Convalescent plasma treatment reduced mortality in patients with severe pandemic influenza A (H1N1) 2009 virus infection. Clin Infect Dis. 2011;52 (4):447-456. doi:10.1093/cid/ciq106

4. Zhou B, Zhong N, Guan Y. Treatment with convalescent plasma for influenza A (H5N1) infection. $N$ Engl J Med. 2007;357(14): 1450-1451. doi:10.1056/NEJMc070359

5. Cheng Y, Wong R, Soo Y, et al. Use of convalescent plasma therapy in SARS patients in Hong Kong. Eur J Clin Microbiol Infect Dis. 2005;24(1):44-46. doi:10.1007/s10096-004-1271-9

6. Shen C, Wang Z, Zhao F, et al. Treatment of 5 critically ill patients with COVID-19 with convalescent plasma. JAMA. 2020;323 (16):1582-1589. doi:10.1001/jama.2020.4783

7. Mair-Jenkins J, Saavedra-Campos M, Baillie JK, et al. The effectiveness of convalescent plasma and hyperimmune immunoglobulin for the treatment of severe acute respiratory infections of viral etiology: a systematic review and exploratory meta-analysis. $J$ Infect Dis. 2015;211(1):80-90. doi:10.1093/infdis/jiu396

8. Hotez PJ, Corry DB, Bottazzi ME. COVID-19 vaccine design: the janus face of immune enhancement. Nat Rev Immunol. 2020;20 (6):347-348. doi:10.1038/s41577-020-0323-4

9. Jia X, Zhang P, Tian Y, et al. Clinical significance of IgM and IgG test for diagnosis of highly suspected COVID-19 infection. medRxiv. 2020.

10. Jiang HW, Li Y, Zhang HN, et al. Global profiling of SARS-CoV-2 specific $\mathrm{IgG} / \mathrm{IgM}$ responses of convalescents using a proteome microarray. medRxiv. 2020.

11. Wu F, Wang A, Liu M, et al. Neutralizing antibody responses to SARS-CoV-2 in a COVID-19 recovered patient cohort and their implications. medRxiv. 2020:2020-033020047365. doi:10.1101/2020.03.

12. Iwasaki A, Yang Y. The potential danger of suboptimal antibody responses in COVID-19. Nat Rev Immunol. 2020;1-3.

13. Wang Q, Zhang L, Kuwahara K, et al. Immunodominant SARS coronavirus epitopes in humans elicited both enhancing and neutralizing effects on infection in non-human primates. ACS Infect Dis. 2016;2(5):361-376. doi:10.1021/acsinfecdis.6b00006

14. Lu LL, Suscovich TJ, Fortune SM, Alter G. Beyond binding: antibody effector functions in infectious diseases. Nat Rev Immunol. 2018;18(1):46.

15. Xu Z, Shi L, Wang Y, et al. Pathological findings of COVID-19 associated with acute respiratory distress syndrome. Lancet Respir Med. 2020;8(4):420-422. doi:10.1016/S2213-2600(20)30076-X

16. Amanat F, Krammer F. SARS-CoV-2 vaccines: status report. Immunity. 2020;52(4):583-589. doi:10.1016/j.immuni.2020.03.007

17. Burton DR, Poignard P, Stanfield RL, Wilson IA. Broadly neutralizing antibodies present new prospects to counter highly antigenically diverse viruses. Science. 2012;337(6091):183-186. doi:10.1126/ science. 1225416
18. Lu C-L, Murakowski DK, Bournazos S, et al. Enhanced clearance of HIV-1-infected cells by broadly neutralizing antibodies against HIV1 in vivo. Science. 2016;352(6288):1001-1004. doi:10.1126/science. aaf1279

19. Yasui F, Kohara M, Kitabatake M, et al. Phagocytic cells contribute to the antibody-mediated elimination of pulmonary-infected SARS coronavirus. Virology. 2014;454:157-168. doi:10.1016/j.virol.2014. 02.005

20. Strohl WR. Current progress in innovative engineered antibodies. Protein Cell. 2018;9(1):86-120.

21. Sullivan N. Antibody-mediated enhancement of viral disease. Curr Top Microbiol Immunol. 2001;260:145-169.

22. Wang S-F, Tseng S-P, Yen C-H, et al. Antibody-dependent SARS coronavirus infection is mediated by antibodies against spike proteins. Biochem Biophys Res Commun. 2014;451(2):208-214. doi:10.1016/j.bbrc.2014.07.090

23. Jaume M, Yip MS, Cheung CY, et al. Anti-severe acute respiratory syndrome coronavirus spike antibodies trigger infection of human immune cells via a $\mathrm{pH}$-and cysteine protease-independent Fc $\gamma \mathrm{R}$ pathway. $J$ Virol. 2011;85(20):10582-10597. doi:10.1128/JVI.00 671-11

24. Thomson CA. Igg Structure and Function. 2016.

25. Shackelford PG, Granoff DM, Polmar SH, et al. Subnormal serum concentrations of $\mathrm{IgG} 2$ in children with frequent infections associated with varied patterns of immunologic dysfunction. J Pediatr. 1990;116 (4):529-538. doi:10.1016/S0022-3476(05)81598-7

26. Umetsu DT, Ambrosino DM, Quinti I, Siber GR, Geha RS. Recurrent sinopulmonary infection and impaired antibody response to bacterial capsular polysaccharide antigen in children with selective IgG-subclass deficiency. $N$ Engl J Med. 1985;313(20):1247-1251. doi:10.1056/NEJM198511143132002

27. Yuan FF, Tanner J, Chan P, et al. Influence of FcyRIIA and MBL polymorphisms on severe acute respiratory syndrome. Tissue Antigens. 2005;66(4):291-296. doi:10.1111/j.1399-0039.2005.00476.x

28. Bartmann P, Grosch-Wörner I, Wahn V, Belohradsky BH. IgG2 deficiency in children with human immunodeficiency virus infection. Eur J Pediatr. 1991;150(4):234-237. doi:10.1007/BF01955519

29. Xu W, Santini PA, Sullivan JS, et al. HIV-1 evades virus-specific IgG2 and IgA responses by targeting systemic and intestinal B cells via long-range intercellular conduits. Nat Immunol. 2009;10(9):1008. doi:10.1038/ni.1753

30. Martinez V, Costagliola D, Bonduelle O, et al. Combination of HIV-1-specific CD4 Th1 cell responses and IgG2 antibodies is the best predictor for persistence of long-term nonprogression. $J$ Infect Dis. 2005;191(12):2053-2063. doi:10.1086/430320

31. Long Q-X, Liu B-Z, Deng H-J, et al. Antibody responses to SARS-CoV-2 in patients with COVID-19. Nat Med. 2020;1-4.

32. Zhou Z, Ren L, Zhang L, et al. Heightened innate immune responses in the respiratory tract of COVID-19 patients. Cell Host Microbe. 2020;27(6):883-890.e2. doi:10.1016/j.chom.2020.04.017

33. Zheng M, Gao Y, Wang G, et al. Functional exhaustion of antiviral lymphocytes in COVID-19 patients. Cell Mol Immunol. 2020;17 (5):533-535. doi:10.1038/s41423-020-0402-2

34. Trouillet-Assant S, Viel S, Gaymard A, et al. Type I IFN immunoprofiling in COVID-19 patients. J Allergy Clin Immunol. 2020;146 (1):206-208.e2. doi:10.1016/j.jaci.2020.04.029

35. Liu Y, Zhang C, Huang F, et al. Elevated plasma level of selective cytokines in COVID-19 patients reflect viral load and lung injury. Natl Sci Rev. 2020.

36. Sun B, Feng Y, Mo X, et al. Kinetics of SARS-CoV-2 specific IgM and IgG responses in COVID-19 patients. Emerg Microbes Infect. 2020; (just-accepted):1-36.

37. Zhang B, Zhou X, Zhu C, et al. Immune phenotyping based on the neutrophil-to-lymphocyte ratio and IgG level predicts disease severity and outcome for patients with COVID-19. Front Mol Biosci. 2020;7:157. doi:10.3389/fmolb.2020.00157 
38. Tan W, Lu Y, Zhang J, et al. Viral kinetics and antibody responses in patients with COVID-19. MedRxiv. 2020.

39. Abdullah SF, Sharquie IK. SARS-CoV-2: a piece of bad news. Medeniyet Med J. 2020;35(2):151.

40. Wan Y, Shang J, Sun S, et al. Molecular mechanism for antibody-dependent enhancement of coronavirus entry. $J$ Virol. 2020;94(5).

41. García-Sastre A, Biron CA. Type 1 interferons and the virus-host relationship: a lesson in detente. Science. 2006;312(5775):879-882. doi:10.1126/science. 1125676

42. Channappanavar R, Fehr AR, Zheng J, et al. IFN-I response timing relative to virus replication determines MERS coronavirus infection outcomes. J Clin Invest. 2019;129(9):3625-3639. doi:10.1172 JCI126363

43. Blanco-Melo D, Nilsson-Payant BE, Liu W-C, et al. Imbalanced host response to SARS-CoV-2 drives development of COVID-19. Cell. 2020;181(5):1036-1045.e9. doi:10.1016/j.cell.2020.04.026

44. Hadjadj J, Yatim N, Barnabei L, et al. Impaired type I interferon activity and exacerbated inflammatory responses in severe Covid-19 patients. MedRxiv. 2020.

45. Channappanavar R, Fehr AR, Vijay R, et al. Dysregulated type $\mathrm{I}$ interferon and inflammatory monocyte-macrophage responses cause lethal pneumonia in SARS-CoV-infected mice. Cell Host Microbe. 2016;19(2):181-193. doi:10.1016/j.chom.2016.01.007

46. Lokugamage KG, Hage A, Schindewolf C, Rajsbaum R, Menachery VD. SARS-CoV-2 is sensitive to type I interferon pretreatment. BioRxiv. 2020.

47. Wang $X$, Mathieu M, Brezski RJ. IgG Fc engineering to modulate antibody effector functions. Protein Cell. 2018;9(1):63-73. doi:10.1007/s13238-017-0473-8

48. Holliger P, Hudson PJ. Engineered antibody fragments and the rise of single domains. Nat Biotechnol. 2005;23(9):1126-1136. doi:10.1038/ nbt1142

49. Lilly E. Lilly begins world's first study of a potential covid-19 antibody treatment in humans; 2020. Available from: https://www.prnews wire.com/news-releases/lilly-begins-worlds-first-study-of-a-potentialcovid-19-antibody-treatment-in-humans-301068303.html. Accessed September 5, 2020.

50. An Z, Forrest G, Moore R, et al. $\operatorname{IgG} 2 \mathrm{~m} 4$, an engineered antibody isotype with reduced Fc function. Paper presented at: MAbs; 2009.

51. Vafa O, Gilliland GL, Brezski RJ, et al. An engineered Fe variant of an IgG eliminates all immune effector functions via structural perturbations. Methods. 2014;65(1):114-126. doi:10.1016/j.ymeth.20 13.06.035
52. Prabhu M, Riley LE. Universal screening and vaccination for hepatitis b in pregnancy: the time is now. Obstet Gynecol. 2020;135 (4):808-811. doi:10.1097/AOG.0000000000003706

53. Zhu F-C, Li Y-H, Guan X-H, et al. Safety, tolerability, and immunogenicity of a recombinant adenovirus type-5 vectored COVID-19 vaccine: a dose-escalation, open-label, non-randomised, first-inhuman trial. Lancet. 2020

54. Coleman CM, Liu YV, Mu H, et al. Purified coronavirus spike protein nanoparticles induce coronavirus neutralizing antibodies in mice Vaccine. 2014;32(26):3169-3174. doi:10.1016/j.vaccine.2014.04.016

55. Jiang S, Bottazzi ME, Du L, et al. Roadmap to developing a recombinant coronavirus $\mathrm{S}$ protein receptor-binding domain vaccine for severe acute respiratory syndrome. Expert Rev Vaccines. 2012;11(12):1405-1413. doi:10.1586/erv.12.126

56. Bournazos S, Wang TT, Ravetch JV. The role and function of Fcy receptors on myeloid cells. Myeloid Cells Health Dis. 2017;405-427.

57. Gralinski LE, Sheahan TP, Morrison TE, et al. Complement activation contributes to severe acute respiratory syndrome coronavirus pathogenesis. MBio. 2018;9(5):e01753-01718. doi:10.1128/ mBio.01753-18

58. Singh I, McConnell I, Dalziel R, Blacklaws BA. Serum containing ovine IgG2 antibody specific for maedi visna virus envelope glycoprotein mediates antibody dependent cellular cytotoxicity. Vet Immunol Immunopathol. 2006;113(3-4):357-366. doi:10.1016/j. vetimm.2006.06.006

59. Duff G. Expert Scientific Group on Phase One Clinical Trials: Interim Report. 2006.

60. Coffman RL, Savelkoul HF, Lebman DA. Cytokine regulation of immunoglobulin isotype switching and expression. Semin Immunol. 1989;1(1):55-63.

61. French MA, Tanaskovic S, Law MG, et al. Vaccine-induced IgG2 anti-HIV p24 is associated with control of HIV in patients with a 'high-affinity'Fc $\gamma$ RIIa genotype. AIDS. 2010;24(13):1983-1990. doi:10.1097/QAD.0b013e32833c1ce0

62. Shearer WT, Israel RJ, Starr S, et al. Recombinant CD4-IgG2 in human immunodeficiency virus type 1 -infected children: phase $1 /$ 2 study. J Infect Dis. 2000;182(6):1774-1779. doi:10.1086/317622

63. Lau C, Gunnarsen KS, Høydahl LS, et al. Chimeric anti-CD14 IGG2/ 4 hybrid antibodies for therapeutic intervention in pig and human models of inflammation. J Immunol. 2013;191(9):4769-4777. doi:10.4049/jimmunol.1301653

64. Rogers TF, Zhao F, Huang D, et al. Isolation of potent SARS-CoV-2 neutralizing antibodies and protection from disease in a small animal model. Science;2020:eabc7520. doi:10.1126/science.abc7520
ImmunoTargets and Therapy

\section{Publish your work in this journal}

ImmunoTargets and Therapy is an international, peer-reviewed open access journal focusing on the immunological basis of diseases, potential targets for immune based therapy and treatment protocols employed to improve patient management. Basic immunology and physiology of the immune system in health, and disease will be also covered. In addition, the journal will focus on the impact of management programs and new therapeutic agents and protocols on patient perspectives such as quality of life, adherence and satisfaction. The manuscript management system is completely online and includes a very quick and fair peer-review system, which is all easy to use. Visit http://www.dovepress.com/testimonials.php to read real quotes from published authors. 